\title{
Atenção Primária à Saúde para mulheres privadas de liberdade
}

\author{
Primary Health Care for women deprived of freedom
}

Atención Primaria de Salud para mujeres privadas de libertad

Laura Caldeira Souza ${ }^{1 *}$, Anna Henriques Alcure ${ }^{1}$, Bianca Perim Bernardo ${ }^{1}$, João Luís Magalhães Albuquerque Gonçalves ${ }^{1}$, João Pedro Miguez Pintoº , Laura Fernandes Comelli Figueira' ${ }^{1}$, Thâmella Barbosa Ferreira ${ }^{1}$, Vanda Carolina Gomes Damasceno ${ }^{1}$, Mônica Isaura Corrêa ${ }^{3}$.

\section{RESUMO}

Objetivo: Discorrer sobre a realidade das mulheres privadas de liberdade, levando como base as variáveis de saúde em seu aspecto não só de ausência de doença, mas também de bem-estar individual e coletivo. Revisão bibliográfica: O Brasil é um dos países que mais prende mulheres no mundo, estabelecendo um perfil carcerário extremamente variável e com demandas específicas. Nessa conjuntura, é elencado o conjunto de direitos educacionais, jurídicos, religiosos e de saúde que garantem a vida da população carcerária feminina, em detrimento às inóspitas condições em que as mesmas estão instaladas, que contribuem para a retroalimentação do quadro de violência e para a estigmatização das pessoas privadas de liberdade. Esse estudo empenha-se na pesquisa da atenção à saúde dentro das unidades de detenção, para a exposição, com base em fatos, do que não é funcional. Além disso, examina as diretrizes pré-estabelecidas de atenção à saúde da mulher dentro do sistema carcerário brasileiro tendo como base leis vigentes responsáveis por assegurar o direito a saúde. Considerações finais: Torna-se evidente a situação de vulnerabilidade que circunda as mulheres privadas de liberdade.

Palavras-chave: Saúde da mulher, Atenção primária à saúde, Prisioneiros.

\begin{abstract}
Objective: To discuss the reality of women deprived of liberty, based on health variables in their aspect, not only of absence of disease, but also of individual and collective well-being. Bibliographic review: Brazil is one of the countries that most detains women in the world, establishing an extremely variable prison profile and with specific demands. In this context, the set of educational, legal, religious and health rights that guarantee the life of the female prison population is listed to the detriment of the inhospitable conditions in which they are installed, which contribute to the feedback of the situation of violence and to stigmatization of people deprived of their liberty. This study is committed to researching health care within detention facilities, to expose, based on facts, what is not functional. In addition, it examines the pre-established guidelines for women's health care within the Brazilian prison system based on the laws in force responsible for ensuring the right to health. Final considerations: The situation of vulnerability surrounding women deprived of liberty becomes evident.
\end{abstract}

Key words: Women's health, Primary health care, Prisoners.

${ }^{1}$ Centro Universitário UNIFACIG (UNIFACIG), Manhuaçu - MG. *E-mail: lauracaldeira21@ @otmail.com

2 Universidade Salvador (UNIFACS), Salvador - BA.

${ }^{3}$ Centro Universitário de Caratinga, Caratinga - MG.

SUBMETIDO EM: 4/2021

ACEITO EM: 5/2021

PUBLICADO EM: 5/2021 


\section{RESUMEN}

Objetivo: Discutir la realidad de las mujeres privadas de libertad, con base en variables de salud en su aspecto, no solo de ausencia de enfermedad, sino también de bienestar individual y colectivo. Revisión bibliográfica: Brasil es uno de los países que más detenciones de mujeres en el mundo, estableciendo un perfil carcelario extremadamente variable y con demandas específicas. En este contexto, se enlista el conjunto de derechos educativos, legales, religiosos y de salud que garantizan la vida de la población reclusa femenina, en detrimento de las inhóspitas condiciones en las que se encuentran instaladas, que contribuyen a la retroalimentación de la situación de violencia. ya la estigmatización de las personas privadas de libertad. Este estudio se compromete a investigar la atención médica dentro de los centros de detención, para exponer, con base en hechos, lo que no es funcional. Además, examina los lineamientos preestablecidos para la atención de la salud de la mujer dentro del sistema penitenciario brasileño con base en las leyes vigentes encargadas de garantizar el derecho a la salud. Consideraciones finales: Se evidencia la situación de vulnerabilidad que rodea a las mujeres privadas de libertad.

Palabras clave: Salud de la mujer, Atención primaria de salud, Prisioneros.

\section{INTRODUÇÃO}

A saúde voltada para pessoas em estado de reclusão, embora considerada um direito fundamental e constitucional do ser humano, ainda é uma questão negligenciada pelo poder público. Alguns dos princípios do Sistema Único de Saúde (SUS), como o princípio da equidade, preveem que as práticas e os cuidados em saúde dentro dos ambientes de privação de liberdade devem ser ofertados de maneira equivalente àquelas oferecidas à comunidade em geral, visando tratamentos e mecanismos diferenciados de acordo com suas necessidades (ARINDE EL e MENDONÇA MH, 2019). De maneira geral, a atenção à saúde para pessoas privadas de liberdade, voltada principalmente para as mulheres reclusas, é uma questão sanitária relevante e uma grande necessidade de saúde pública (GRAÇA BC, et al., 2018).

Segundo estudos da Diretoria de Análises Públicas da Fundação Getúlio Vargas (Dapp/FGV), o Brasil se encontra entre os três países com a maior população carcerária de mulheres no mundo, tendo crescido em $700 \%$ o número de detentas no período de 2000 a 2016. Levando em consideração esse levantamento de dados, faz-se necessário atentar-se para um maior direcionamento da rede de Atenção Primária à Saúde, no que se refere à promoção e à prevenção de saúde desta parcela populacional (SANTOS MV, et al., 2017).

$\mathrm{Na}$ prisão, as condições de cárcere, muitas vezes, delimitam o processo entre saúde e doença. É desafiador a atenção às necessidades de que cada pessoa privada de liberdade se encontra, por exemplo o tamanho das celas, ser portador de alguma comorbidade (diabetes, hipertensão, depressão), acesso à higiene pessoal e à alimentação limitados (SANTOS MV, et al., 2017). É importante destacar o crescente incremento dos índices de encarceramento feminino, a situação precária em que muitos dos presídios se encontram, a superlotação, a debilidade estrutural e de planejamento, bem como a falta de acompanhamento médico adequado para necessidades intrínsecas de uma mulher, como o acompanhamento reprodutivo, prénatal, parto, puerpério, entre outros (VALIM EMA, et al., 2018). Nesse sentido, fica evidente que as condições de vida e de confinamento, hábitos, alimentação e cuidados, influenciam diretamente na condição de saúdedoença das mulheres encarceradas (GRAÇA BC, et al., 2018).

Além disso, existe uma série de fatores que influenciam neste processo de encarceramento. A família, quando encontrada em situação frágil e de desestrutura, se apresenta como fator importante que influencia no comportamento do ser humano, seja ele delituoso ou não, haja vista que esse laço de convivência é responsável pelo desenvolvimento do indivíduo e formação de seu caráter. Por conseguinte, o processo de aceitação da situação de privação da liberdade, muitas vezes vem acompanhado de angústia, sentimento de culpa, julgamentos e cobranças familiares. E assim, com esse ambiente totalmente novo e esse misto de sentimentos, pode fazer com que a saúde mental dessas mulheres fique prejudicada (GUSMÃO MAJX, et al., 2019). 
Ademais, ao considerar que a saúde não é somente a ausência de doenças, mas um processo diretamente ligado ao completo bem-estar corpóreo, de maneira a integrar, também, a saúde física, psíquica e social, pode-se constatar que o ambiente penitenciário afeta diretamente no bem-estar físico e psíquico (SANTOS $\mathrm{MV}$, et al. (2017). A insalubridade, hostilidade e o crescimento populacional que tornam 0 ambiente sobrecarregado, aumenta, de maneira significativa, o risco de contaminação por doenças transmissíveis como a sífilis, HIV e tuberculose, e não transmissíveis, como a diabetes, hipertensão e os diversos tipos de cânceres (LÖBO MP, et al., 2019).

Por fim, o objetivo do presente estudo é analisar o cenário de saúde nas penitenciárias femininas, por meio de uma revisão narrativa, a fim de evidenciar as demandas e vulnerabilidades das mulheres privadas de liberdade dentro do ambiente carcerário, buscando expor a efetividade e resolutividade das medidas assistencialistas existentes. Além disso, visa dar ênfase aos direitos das mulheres no que tange à Atenção Primária à Saúde e discorrer acerca da garantia desses direitos, tendo por base todos os princípios e diretrizes do SUS.

\section{REVISÃO BIBLIOGRÁFICA}

\section{Estrutura das prisões femininas e as consequências para a saúde}

A fim de melhor compreender o contexto que leva mulheres ao encarceramento, é necessário reconhecer que as prisões são microcosmos da sociedade em geral e, por isso, apresentam aspectos que comumente são vistos entre os não presos. Estes aspectos são muito mais acentuados no ambiente carcerário, visto que situações absurdas como a insalubridade, por exemplo, representam uma normalidade de muitas prisões brasileiras (SANTOS MV, et al., 2017).

A dinâmica do cárcere e sua estrutura não foram pensadas para mulheres. A lógica masculina que sustenta as prisões impõe condições incompatíveis ao mínimo de dignidade às presas e postergam suas demandas (SCHERER ZAP, et al., 2019), levando à situações que vão na contramão do mais moderno conceito de saúde, que não é apenas a ausência de patologias, mas um completo bem-estar físico, mental e social. Ao analisar a realidade prisional feminina no país, é quase impossível encontrar mulheres em estado saudável, já que mesmo que não possuam as comuns doenças dentro do cárcere, vivem em situações que comprometem significativamente o bem-estar, como a insalubridade, que aumenta a possibilidade de doenças de pele, por exemplo (SANTOS MV, et al., 2017).

Além disso, pontua-se, também, de maneira mais específica, acerca da estrutura física das prisões. Ainda de acordo com Scherer ZAP, et al. (2019), as cadeias são espaços públicos, mas é possível correlacionar as celas femininas ao âmbito privado, considerando que o ambiente doméstico é destinado socialmente como o espaço por excelência da mulher. Já o espaço público é identificado como território masculino. Dessa forma, evidencia-se, ainda mais, a prisão como uma miniatura aguçada do mundo externo.

\section{Saúde mental das mulheres privadas de liberdade}

As deficiências estruturais no sistema penitenciário brasileiro reforçam a cultura de violência institucional, favorecendo práticas e abordagens que ferem a dignidade e violam os direitos humanos, como a superlotação e a higiene precária (LOPES TC e PINHEIRO R, 2016). Essa situação se estende para os setores da saúde, uma vez que a população feminina que se encontra encarcerada, no que tange ao deterioramento salutar, é mais afetada em relação à população feminina em geral. Sob a ótica dessa atitude pusilânime, percebe-se que as políticas públicas de saúde destinadas às mulheres encarceradas não abarcam toda essa parcela marginalizada da sociedade, fato que vai de encontro ao conceito de saúde pleiteado pela Constituição Federal, a qual é considerada um direito fundamental e inviolável dos indivíduos brasileiros, sejam estes livres ou privados de liberdade (AUDI CAF, et al., 2016).

À vista disso, a estrutura física precária, a inacessibilidade a determinados procedimentos de saúde que são realizados fora do âmbito carcerário, a escassez de materiais e o descaso com a saúde da população encarcerada feminina, podem acarretar estados de desequilíbrios psíquicos (ARAUJO MM, et al., 2020). 
No nível psicobiológico, é válido destacar que a adaptação e a aceitação do âmbito novo em que as detentas estão inseridas, tornam-se essenciais para que o processo de encarceramento seja menos doloroso. As unidades prisionais podem apresentar condições insalubres no que tange à higiene, à superlotação e à baixa circulação de ar, fato que interfere no bem-estar da população feminina encarcerada, gerando frustração por não terem suas necessidades básicas atendidas (BARCINSKI M, et al., 2013). Destarte, a carência de cuidados básicos, como limpeza e alimentação correta, interferem, diretamente, no quadro psíquico das mulheres encarceradas, posto que o desequilíbrio da qualidade de vida está ligado ao processo de saúdedoença (ARAUJO MM, et al., 2020).

No que diz respeito ao nível psicossocial, é recorrente o abandono familiar da população encarcerada feminina, fato que ocasiona um sentimento de solidão nessas mulheres, haja vista que as detentas almejam a manutenção dos vínculos familiares como forma de auxiliar no enfrentamento da situação em que vivem (DINIZ D, 2015). Diante desse cenário, a segregação familiar é tida como um dos fatores mais dolorosos para o cotidiano das presas, as quais tendem a sofrer mais com esse processo de distanciamento, posto que as detentas deixam para trás, determinadas referências da sua própria identidade na sociedade, como ser mãe ou ser filha, o que interfere diretamente na sua autonomia e personalidade (SCHERER ZAP, et al., 2020).

Dessa forma, as vulnerabilidades no que tange às mulheres privadas de liberdade são maximizadas, haja vista que a reclusão, de modo geral, relaciona-se às conexões afetivas e ao anseio pela redução das displicências diárias na prisão; contudo, o encarceramento proporciona um distanciamento dos seus familiares e amigos, um possível fim de relacionamento estável e baixa disponibilidade para criação dos seus filhos, o que tende a propiciar estados de tristeza e quadros depressivos, além da ansiedade em relação aos cuidados dados aos familiares que estão livres (GRAÇA BC, et al., 2018).

Ainda no âmbito psicossocial, o pensamento de determinadas presas em relação ao seu futuro, no momento em que forem libertadas, é marcado por sentimentos de angústia e de preocupação, haja vista que há uma intensa segregação em relação à parcela da população que fora encarcerada, as quais carregam, de maneira errônea, o estigma de criminosos, mesmo após cumprirem a detenção. Diante disso, nota-se que o descaso social, o preconceito e a negligência do sistema prisional contribuem para dificultar a reinserção das detentas na sociedade. Sob esse viés, após saírem do encarceramento, as mulheres encontram-se totalmente desamparadas perante o retorno ao convívio social, onde a discriminação e os estereótipos serão os principais obstáculos dessas cidadãs. Assim, diante da inobservância social em relação à inserção das exdetentas, essas mulheres se sentem desprotegidas por não apresentarem, em um primeiro momento, a consolidação de um futuro, visto que essa população carcerária anseia por encontrar algum meio de subsistência (SCHERER ZAP, et al., 2020).

Segundo Oliveira KRV, et al. (2020), em sua pesquisa, ao longo do período em que as mulheres foram mantidas em cárcere pelo sistema prisional, foi possível perceber em seus discursos, inúmeros sentimentos negativos, como tristeza, angústia, dor, solidão, sensação de abandono e revolta, os quais se tornam fontes de estresse para as detentas, comprometendo, dessa forma, sua saúde mental. Outrossim, destaca-se que a ausência de programas de saúde eficientes, colabora para a condição desumana em que as detentas enfrentam no âmbito carcerário, posto que o direito à saúde é pleiteado pela Constituição Federal, no artigo 196.

Diante das problemáticas enfrentadas pelas mulheres encarceradas, a exemplo da violência física e mental, nota-se que muitas optam por atividades para ocuparem seu tempo e, de certa forma, Ihes trazerem oportunidades posteriormente, como a realização de trabalhos dentro do presídio e o ingresso em projetos educacionais. Desse modo, a execução de tais tarefas reduz a ansiedade e a tristeza de viver em um ambiente privado de liberdade, além de propiciar formas de amenizar as dores do distanciamento da família e da sociedade (OLIVEIRA KRV, et al., 2020).

\section{Relação do cárcere com as Infecções Sexualmente Transmissíveis}

O Brasil, enquanto país obtém em seu contexto, grande número populacional carcerário, ficando atrás apenas dos Estados Unidos da América (EUA) e China. Sendo assim, é primordial a compreensão dos 
agravos em saúde nestes ambientes (BENEDETTI MSG, et al., 2020). Tais locais devem ser vistos como campo de atuação profissional importante, já que no sistema prisional existe um elevado número de afecções contagiosas, entre elas, as inúmeras Infecções Sexualmente Transmissíveis (IST 's) (LESSA PRA, et al., 2012).

Os presídios, em sua maioria, encontram-se em uma precariedade no ramo da saúde, principalmente o que propicia o aumento do número de ISTs. Entre as IST 's mais relatadas no ambiente de cárcere, estão às afecções pelo vírus da imunodeficiência humana (HIV), sífilis, hepatite e câncer de colo do útero. Em estudo feito por Benedetti MSG, et al. (2020), em cadeia pública feminina de Boa Vista (Roraima), abrangendo amostra composta por 168 detentas, a prevalência de HIV, sífilis e hepatite B foram de, respectivamente, 0 a $26 \%$; 2,2 a 22,8\%; 3,8 a 26,4\%. Outrossim, o câncer de colo de útero, por sua vez, fica abaixo apenas do acometimento por câncer de mama (LESSA PRA, et al., 2012).

Alguns fatores de risco que levam ao público feminino privado de liberdade adquirirem essas patologias são: ausência de acesso à rede de saúde com facilidade e frequência necessárias, ausência de informações e orientações dentro das celas, baixa escolaridade, início precoce de atividades sexuais, obtenção de muitos parceiros sexuais, baixo nível socioeconômico aliado ao uso inadequado ou não utilização de preservativos, uso de drogas e o compartilhamento de objetos perfurocortantes, como agulhas e seringas (LESSA PRA, et al., 2012).

A questão do elevado número de pessoas no sistema prisional é bem discutida como favorecedora da disseminação das IST 's. Os ambientes carcerários, com grande presença de aglomerações, ausência de iluminação adequada, quadros de abusos sexuais e violência, sem contar no histórico de muitas dessas mulheres privadas de liberdade, que muitas vezes já encararam situações de uso de drogas ilícitas, corroboram à facilidade para o aumento dos casos de IST's (BENEDETTI MSG, et al., 2020).

A concepção de toda esta problemática é associada, para essas mulheres privadas de liberdade, à exclusão, ausência de moral perante a sociedade, e, em diversos momentos, surgimento de angústia, dor e solidão, que causam elevado estresse e dificultam o processo de ressocialização (OLIVEIRA KRV, et al., 2020). Segundo Graça BC, et al. (2018), muitas mulheres relatam que "a dor tem que aparecer para que eu tenha acesso", ou seja, é como se a condição de estar do lado de dentro de uma cela em sistema prisional as impossibilitassem de adquirir o acesso à saúde adequado. Não obstante, muitas IST's são entendidas por esse público como uma condenação direta à morte, como o HIV. Contudo, entende-se que a via de propagação destas patologias não se dá unicamente sexual, mas também engloba parâmetros de ineficiência de cuidados e orientação em saúde (TRIGUEIRO DRSG, et al., 2016).

A Organização Mundial de Saúde (OMS) prevê, no que tange sobre essas patologias, que os profissionais da saúde devem corroborar à educação e clareza sobre os meios de prevenção e como são transmitidas as IST`s. Já é garantido por lei o direito à saúde das mulheres privadas de liberdade, porém esse direito é omitido e não cumprido pelo Estado (LEOCADIO AF, et al., 2020). Existe outra realidade por trás de toda omissão e estrutura inconsistente em ações que visem tal perspectiva. A falta de assistência médica está rodeada de enfrentamentos, desde o escasso recurso humano e materiais à saúde, o baixo número de profissionais acessíveis, baixo nível salarial de profissionais e a precariedade local a que se destina o atendimento das mulheres privadas de liberdade (BENEDETTI MSG, et al., 2020).

Foi criada, em 1984, a Lei de Execução Penal (LEP), que pontua sobre direitos e deveres de todos os indivíduos em sistema prisional, independentemente de sexo ou gênero. Incluídos nestes direitos estão a assistência jurídica, educacional, social, religiosa e de saúde. Ademais, todos esses direitos devem ser usufruídos pelas pessoas privadas de liberdade a partir do momento que adentram o sistema prisional, até quando for cumprido o último dia de detenção. Entretanto, salienta-se que, por inúmeras vezes, essas recomendações não são praticadas, deixando essas mulheres desamparadas (LERMEN HS, et al., 2015).

Em conjunto à LEP, o Plano Nacional de Saúde no Sistema Penitenciário (PNSSP) fomenta o controle e prevenção de doenças, com diminuição dos agravos na saúde. Desse modo, implica atuação sobre áreas de saúde bucal, saúde da mulher, IST's no geral, saúde mental e outras tantas comorbidades, além do acesso 
à medicação, exames e vacinação. A mulher privada de liberdade, por sua condição, ainda obtém este acesso mediante nexo direto com o sentimento de dor ou também quando em período gestacional, situação delicada a que são expostas, sendo circunstanciadas como minoria (LERMEN HS, et al., 2015).

Em tese, é constatado que todo mecanismo de triagem patológica deve englobar dinâmica de compreensão do modo como ocorre a injúria e a infecção, sem deixar de levar em conta de quais meios dispõe o profissional da saúde para que o serviço ofertado se dê de forma legal e viável (LEOCÁDIO AF, et al., 2020). Embora o direito à saúde das mulheres privadas de liberdade seja garantido por lei e um dever do Estado, notório é o seu descumprimento. Para Scherer ZAP, et al. (2019), os serviços em saúde devem atuar na perspectiva de amortecer o fator exclusão a essa população, não somente quando estas mulheres se inserem no sistema prisional, mas também pós liberdade, ou seja, quando novamente tentam se reinserir no mercado de trabalho ou iniciam um novo caminho em suas vidas. Toda essa polêmica enfatiza que, no Brasil, ainda existem barreiras a nível socioculturais a serem vencidas, tornando necessárias políticas que integrem de forma mais abrangente e universal essas mulheres privadas de liberdade, ao serviço concedido pelo SUS.

\section{Política Nacional de Atenção às Mulheres em Situação de Privação de Liberdade e Egressas do Sistema Prisional}

Em 16 de janeiro de 2014, foi criada a Política de Saúde do Sistema Prisional Brasileiro para as Mulheres Privadas de Liberdade, que criou a Política Nacional de Atenção às Mulheres em Situação de Privação de Liberdade e Egressas do Sistema Prisional, a fim de garantir que, durante o cumprimento da sentença, as mulheres tenham direito à saúde, maternidade, lazer, educação e boa alimentação. Em resumo, acesso aos direitos básicos da vida, visando a promoção e prevenção da saúde (SANTOS MV, et al., 2017).

A alimentação dentro das prisões é de baixa qualidade, sendo assim, não agradável para o consumo e com um número baixo de nutrientes. Isso acaba prejudicando a boa alimentação por parte das detentas, ocasionando uma interrupção na construção de uma população mais satisfeita e mais apta a uma mudança significativa para a vivência em sociedade novamente. Vale ressaltar que a falta de fornecimento de alimentos adequados advém da corrupção e de uma gestão errônea existente no país (DUNCK JAM e SANTOS N, 2017). Com uma alimentação saudável, o desenvolvimento de bons hábitos pode colaborar para que as mulheres privadas de liberdade vivam com mais saúde, evitando o aparecimento de doenças como hipertensão e diabetes mellitus (SANTOS MV, et al., 2017).

Apesar de terem leis que amparam as mulheres privadas de liberdade para que tenham acesso aos direitos básicos, a precariedade na saúde, informação, alimentação e lazer nas prisões, demonstram que essas leis não estão sendo cumpridas com eficiência e com integralidade, o que mostra um aumento de doenças mentais, câncer, hipertensão arterial, diabetes mellitus e IST, por falta de recursos e de profissionais da área da saúde disponíveis para atender essa demanda (GRAÇA BC, et al., 2018).

As famílias das detentas, principalmente as mães, relatam estarem cansadas, tristes e insatisfeitas de verem as filhas em situação de prisão e confessam que após a visita, o retorno à rotina é difícil. Entretanto, ao irem visitar suas filhas, mostram que os laços familiares ainda estão presentes. Com isso, sabe-se que é uma luta diária de aceitação e mudanças, tanto enquanto a mulher permaneça presa, quanto após a sua saída da penitenciária. Nesse âmbito, mostra-se a necessidade que as leis de amparo sejam cumpridas de forma eficiente, tanto para a família quanto para a detenta, sendo possível gerar uma vida em meio social adequado à sobrevivência de boa qualidade (PEREIRA EL, 2016).

\section{CONSIDERAÇÕES FINAIS}

Torna-se evidente a situação de vulnerabilidade que circunda as mulheres privadas de liberdade. Embora existam, as medidas assistenciais, principalmente direcionadas à população carcerária feminina, são ineficientes, além de desrespeitadas na grande maioria dos casos. Em suma, é imprescindível a garantia dos direitos relacionados às mulheres privadas de liberdade no que tange aos princípios básicos de saúde predispostos pelo SUS, além da resolubilidade propostas pelas leis vigentes. 


\section{REFERÊNCIAS}

1. ARAÚJO MM, et al. Assistência à saúde de mulheres encarceradas: análise com base na Teoria das Necessidades Humanas Básicas. Esc Anna Nery, 2020; 24(3):1-7.

2. ARINDE EL; MENDONÇA MH. Política prisional e garantia de atenção integral à saúde da criança que coabita com mãe privada de liberdade, Moçambique. Saúde Debate, 2019; 43(120): 43-53.

3. AUDI CAF, et al. Inquérito sobre condições de saúde de mulheres encarceradas. Saúde Debate, 2016; 40(109):112124.

4. BARCINSKI M, et al. Marianismo e a vitimização de mulheres encarceradas: formas alternativas de exercício do poder feminino. Assoc Port Estud Mulh., 2013; 28: 87-100.

5. BENEDETTI MSG, et al. Infecções sexualmente transmissíveis em mulheres privadas de liberdade em Roraima. Rev Saúde Pública, 2020; 54(105):1-11.

6. DINIZ D. Mulheres na máquina do abandono: a escuta de Debora Diniz num presídio feminino. Revista Estudos Feministas, 2015; 26(1): 1-5.

7. DUNCK JAM, SANTOS N. A efetividade do direito humano à alimentação adequada às pessoas privadas de liberdade nos cárceres brasileiros e o papel das instituições de justiça. Revista de Direitos Humanos e Efetividade, 2017; 3(2):58-73.

8. GRAÇA BC, et al. Dificuldades das mulheres privadas de liberdade no acesso aos serviços de saúde. Rev Bras Promoç Saúde, 2018; 31(2):1-9.

9. GUSMÃO MAJX, et al. Dinâmicas sociais, familiares e vulnerabilidades de mulheres privadas de liberdade. Saúde e Pesquisa, 2019; 12(1):159-168.

10. LEOCADIO AF, et al. Infecções Sexualmente Transmissíveis: vulnerabilidade das mulheres privadas de liberdade. Research, Society and Development, 2020; 9(10):1-18.

11. LERMEN HS, et al. Saúde no cárcere: análise das políticas sociais de saúde voltadas à população prisional brasileira. Physis Revista de Saúde Coletiva, 2015; 25(3): 905-924.

12. LESSA PRA, et al. Presença de lesões intraepiteliais de alto grau entre mulheres privadas de liberdade: estudo documental. Rev. Latino-Am. Enfermagem, 2012; 20(2):1-9.

13. LÖBO MP, et al. Ações de prevenção e enfrentamento das IST/AIDS vivenciadas por mulheres encarceradas. Rev Enferm UERJ, 2019; 27:1-7.

14. LOPES TC, PINHEIRO R. Trajetórias de mulheres privadas de liberdade: práticas de cuidado no reconhecimento do direito à saúde no Centro de Referência de Gestantes de Minas Gerais. Physis Revista de Saúde Coletiva, 2016; 26(4):1193-1212.

15. OLIVEIRA KRV, et al. Percepção de mulheres encarceradas sobre o acesso à saúde como ferramenta de ressocialização. Rev Enferm. UERJ, 2020; 28:1-6.

16. PEREIRA EL. Famílias de mulheres presas, promoção da saúde e acesso às políticas sociais no Distrito Federal, Brasil. Ciência e Saúde Coletiva, 2016; 21(7): 2123-2134.

17. SANTOS MV, et al. A saúde física de mulheres privadas de liberdade em uma penitenciária do estado do Rio de Janeiro. Esc Anna Nery, 2017; 21(2): 1-7.

18. SCHERER ZAP, et al. Mulheres privadas de liberdade: representações sociais de prisão, violência e suas consequências. Rev Bras Enferm., 2020; 73(3):1-9.

19. TRIGUEIRO DRSG, et al. Aids e cárcere: representações sociais de mulheres em situação de privação de liberdade. Rev Esc Enferm USP, 2016; 50(4): 554-561.

20. VALIM EMA, et al. Atenção à saúde de pessoas privadas de liberdade. Revista Bioética, 2018; 26(2): $282-290$. 